\title{
Inflow forecasting for lakes using Artificial Neural Networks
}

\author{
R. K. Suryawanshi ${ }^{1}$, S. S. Gedam ${ }^{1} \&$ R. N. Sankhua ${ }^{2}$ \\ ${ }^{I}$ CSRE, IIT Bombay, Mumbai, India \\ ${ }^{2}$ National Water Academy, Pune, India
}

\begin{abstract}
Artificial lakes or reservoirs are constructed for storing the flood waters available during the rainfall period which can be subsequently used for meeting various water demands. These storage areas are also useful for mitigating the damage caused by floods and droughts. Generally, considering the geographical/topographical aspects, many of the artificial lakes are ideally located in the upper reaches of the catchments where the rainfall is comparatively high and the submergence is comparatively low. In such small catchments, severe storms result in very high inflows entering into the storage areas in a short duration. The conventional tools for inflow forecasting include the stochastic approach in which the results depend on the quantity and quality of the input data. To overcome such limitations, the use of present computing capabilities, Satellite Remote Sensing (SRS) data, Geographical Information System (GIS) as well as Artificial Neural Networks (ANN) tools for the development of a real time inflow forecasting model based on the observed rainfall pattern to advance the forecast time as well as to achieve better forecast accuracy would help immensely in planning the lake operations. This study includes the methodology developed for inflow forecasting using geospatial tools comprising spatial and temporal analysis of the storm events i.e. digital rainfall modeling, estimation of runoff depths using ANN and conversion of runoff depths into inflows. However, this paper discusses a digital rainfall model for isochrone areas of the catchment for spatial rainfall distribution and estimation of runoff depths using ANN. An application example for the Panshet reservoir in the Khadakwasla complex near Pune (India) is used for model calibration and presented.

Keywords: digital rainfall, isochrones, ANN, GIS, SRS, inflow forecasting.
\end{abstract}




\section{Introduction}

Natural as well as artificial lakes or reservoirs are intended for storing the flood waters available during the rainfall period which can be subsequently used for meeting various water demands. Generally, because of geographical/ topographical constraints, the water storage structures are located in the upper reaches of the catchments where the rainfall is comparatively high. As the catchments are small, severe storms occurring in such catchments result in very high flows entering into the reservoirs in very short time duration. If the future trend in the rainfall/runoff situation is not known, reservoir water management becomes critical in view of the fact that the instant decision of storing or releasing the waters may result in an adverse impact either on the performance of the project or for the safety of the structure. To achieve proper management of the instant flood waters, it is essential to know the future trend of inflow into the reservoir. If the reservoir is operated without any inputs about the future inflow situation, it is likely that the incoming peak flood may endanger the hydrological safety of the structure as well as the life and property of the downstream population including the possibility of negation of the planned benefits of the project. Hence, there is an inherent need for every water storage/diversion project to have scientifically developed a real time inflow forecasting system on the basis of site specific data relating to all influencing parameters using the latest technological tools.

\section{Reservoir inflow forecasting}

The World Meteorological Organization in its international glossary of terms in hydrology (WMO [1]) defined inflow/flood forecasting as "the prediction of stage, discharge, time of occurrence and duration of inflow - especially at peak discharge at a specified point on a stream - resulting from precipitation and for snow melt". The inflow into the reservoir is dependent on meteorological, hydrological, physical and geographical parameters existing in the catchment. All these parameters have spatial and temporal variations. Hence, even if the precise and accurate forecasting is not possible, the objective is to achieve more accurate forecast using the latest tools when compared to the conventional methods being in vogue. The latest available tools include hydrologic models, GIS, ANN, etc. For such study, HEC-I, AGricultural Non-Point Source Pollution model (AGNPS) etc. are available. These models can be used to simulate hydrologic processes during flood events. However, in this study for conversion of point rainfall into spatially varied digital rainfall, spatial analyst tool of ARCGIS [2] is used. For an estimation of runoff for smaller temporal durations, ANNs have been used. Overall model calibration, testing and validation are carried out using the observed set of three hourly concurrent rainfall and runoff for the three peak storm events which occurred during the monsoon period in the study area. 


\section{Study area}

The Panshet reservoir catchment is in the Ambi watershed of the Mutha sub basin of the Krishna river basin in Pune district of Maharashtra State in the western India. It has latitudes between $18^{\circ} 17^{\prime} 48^{\prime \prime} \mathrm{N}$ and $18^{\circ} 23^{\prime} 03^{\prime \prime} \mathrm{N}$ and longitudes $73^{\circ} 25^{\prime} 55^{\prime \prime} \mathrm{E}$ and $73^{\circ} 38^{\prime} 00^{\prime \prime} \mathrm{E}$. The areal extent of the watershed is about $116 \mathrm{Sq}$. Km. (Figure 1) The intercepted Panshet reservoir has a storage capacity of about $300 \mathrm{Mm}^{3}$. The time of concentration $\left[\mathrm{T}_{\mathrm{c}}\right]$ for this elongated catchment is about 3 hrs. It is observed that the flow conditions change when the floodwater enters into a reservoir as the travel time of a wave in reservoir is less than that of flood of same magnitude traveling through a natural stream. Hence, time to peak is appreciably advanced, leaving lesser warning/operation time. As there is no planned flood storage, the scope of flood moderation has been considerably limited. Hence the real time inflow forecasting model based on rainfall data is essential for scientific operation of the reservoir for safety as well as optimum use of stored water. Accordingly, the objective of the study is to develop inflow forecasting model based on the real time rainfall data using modern tools for this reservoir.

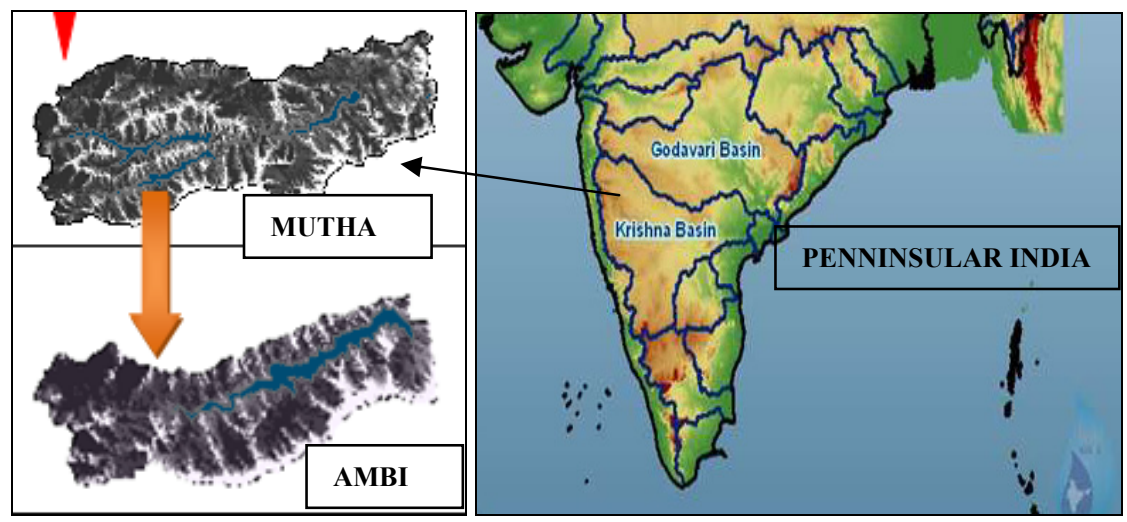

Figure 1: Location map of the study basin.

\section{Methodology}

The study on inflow forecasting basically involves hydrological analysis of various components like rainfall and runoff. Broadly, some of the components involved are rainfall analysis, runoff analysis, establishment of rainfall-runoff relations, establishment of catchment response function for temporal distribution of runoff and routing of flows through channels/reservoirs and establishment of operational rule curve for operation of the reservoir. The methodology flowchart is depicted at Figure 2. It is to state that the spatial distribution of the rainfall on micro scale to estimate digital rainfall, use of ANN for deriving runoff depths, and use of micro level physical and morphological features of the catchment to 
convert runoff depths into reservoir inflows are some of the unique features of this study. The conversion of runoff into inflows including hydrological routing duly taking into account the effect of the reservoir in computation of the inflow hydrograph at the dam site using geospatial tools, and calibration, testing and validation of the model for the study basin are part of this flowchart. However, in this paper the discussion is limited to estimation of digital rainfall using innovative method using advance geospatial tools and estimation of runoff using ANN including its validation using observed events for the study area. The remaining components are under study.

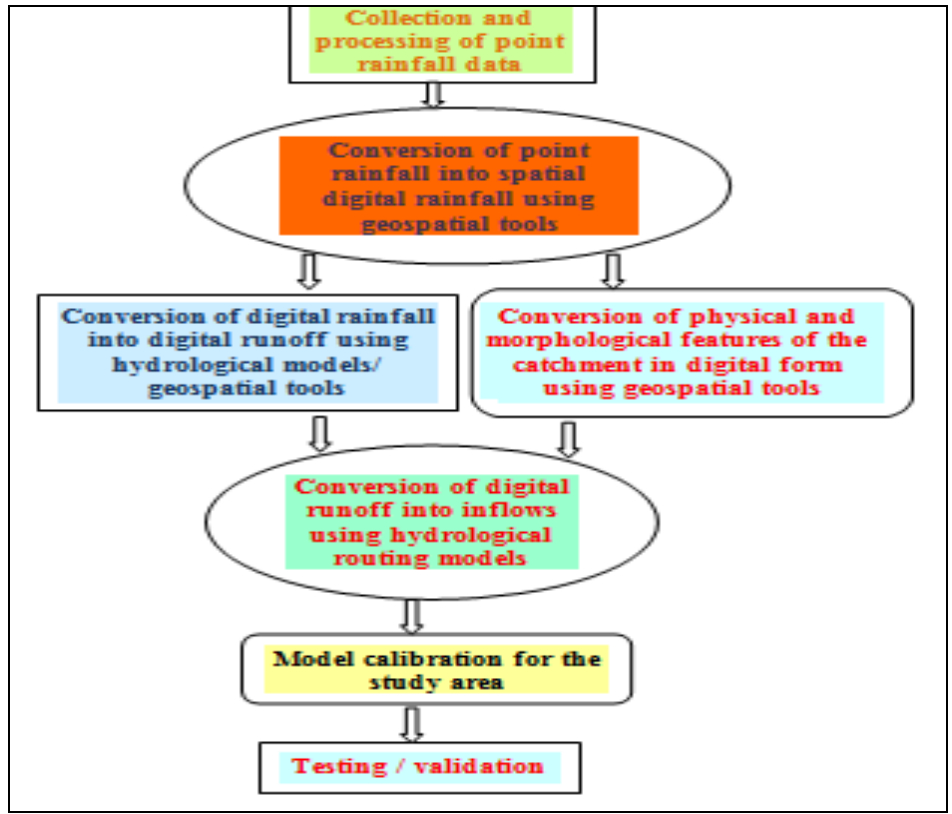

Figure 2: Methodology flowchart.

\section{Digital rainfall estimation}

The point rainfall being the fundamental input in the process, the accuracy in estimation of the average areal rainfall that falls in the catchment during the storm is the primary concern for forecasting the inflows into the reservoir. Ball and Luk [3] have attempted to model the rainfall variation, whereas Narkhedkar et al. [4] used spatial grid for the same. The mean areal value (R) of rainfall over a basin area $A$, having pixel element $\left(d x, d_{y}\right)$ can be expressed as

$$
R=\int_{A} r(x, y) . d_{x} \cdot d_{y} \iint_{A} d_{x} d_{y}
$$

where $\boldsymbol{r}(\boldsymbol{x}, \boldsymbol{y})$ is the rainfall surface function which is never known but can be approximated from the point rainfall values $r_{1}, r_{2}, \ldots, r_{N}$ measured by gauges. 
The simplified results for average areal rainfall can be obtained using geospatial tools. The point rainfall of the four stations collected for the study area is distributed spatially using the innovative concept of Digital Rainfall Model (DRM) which is similar to the concept of Digital Elevation Model (DEM). The pixel wise spatial distribution of rainfall is estimated for each of the three hourly spells of the storm using Inverse Distance Weights (IDW) available in spatial analyst tool in ARC-GIS. The distributed rainfall is again classified in discrete intervals for each of the isochrone polygons which are subsequently converted into average rainfall for the entire catchment based on the all isochrone polygon areas. The sample DRM layer is shown in Figure 3 and the three hourly distributed rainfall hyetograph for the storm event is depicted at Figure 4.

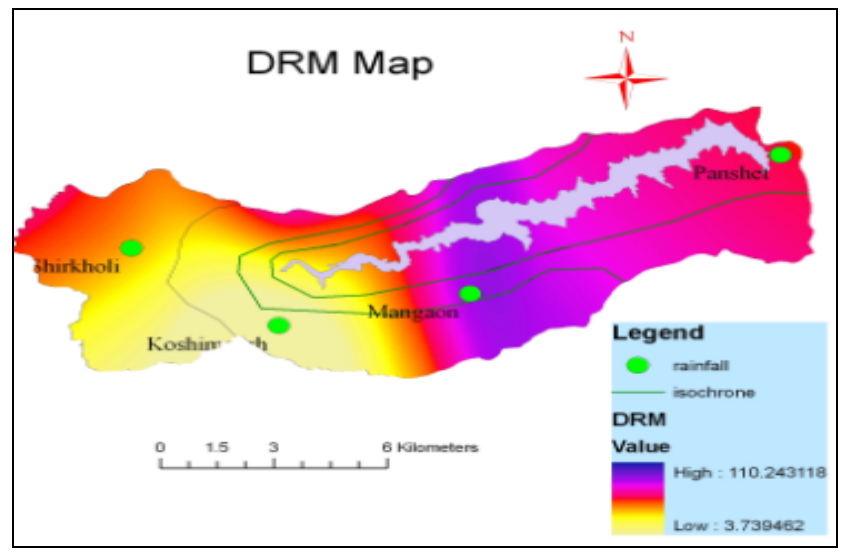

Figure 3: $\quad$ DRM and isochrone layer.

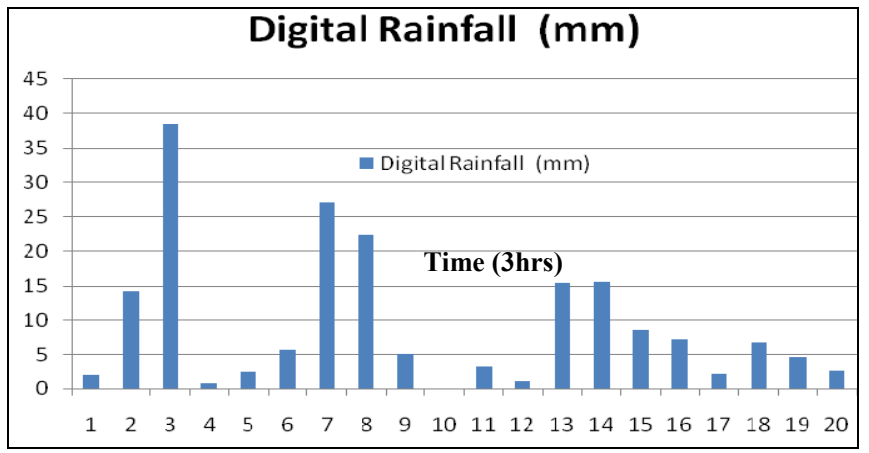

Figure 4: Digital rainfall hyetograph.

\section{Runoff estimation using ANN}

The other important step in inflow forecasting is estimation of runoff depths using appropriate hydrological models. The use of ANN in hydrological analysis 
has become quite common. The technique is being efficiently used as black box model for estimation of various components of storages and processes involved in hydrologic cycle. Tokar and Johnson [5] have attempted to use an ANN methodology to forecast daily runoff as a function of daily precipitation, temperature and snowmelt. Sajikumar and Thandaveswara [6] used artificial neural network paradigm i.e. temporal back propogation-neural network (TBP$\mathrm{NN}$ ) for estimation of runoff from rainfall data on monthly basis. Zealand et al [7] have used ANN for short-term forecasting of stream flows. The model of an artificial neuron closely matches biological neuron. The artificial neuron is a processing element, i.e. a node. The input signals $x_{1}, x_{2}, x_{3} \ldots x_{n}$ are normally continuous variables. The weights can be positive or negative corresponding to acceleration or inhibition respectively of the flow of the signals. The summing node gathers all the input weighted signals and then passes to the output using the transfer function which is usually non-linear. Applying the most commonly used sigmoidal transfer function, the output of typical neuron can be written as

$$
y=1 /\left(1+w^{-a x}\right)
$$

where $\boldsymbol{x}$ is the input, $\boldsymbol{y}$ is the output, $\boldsymbol{w}$ is the weight and $\boldsymbol{a}$ is the coefficient/gain which reflects the slope of the sigmoidal function that changes between the two asymptotic values $(0$ and +1$)$. Training is a process of changing/updating the weights. The back propagation training algorithm is used for a wide variety of applications.

\section{Design of ANN network}

NeuroIntelligence (neural network software) [8] is used in this study to solve the forecasting problem which helps to gain the maximum productivity in preprocessing data, efficient network architecture, analyze performance. Network with five nodes in input layer, eight nodes in one hidden layer and one node as output has been adopted for the study (Figure 5).

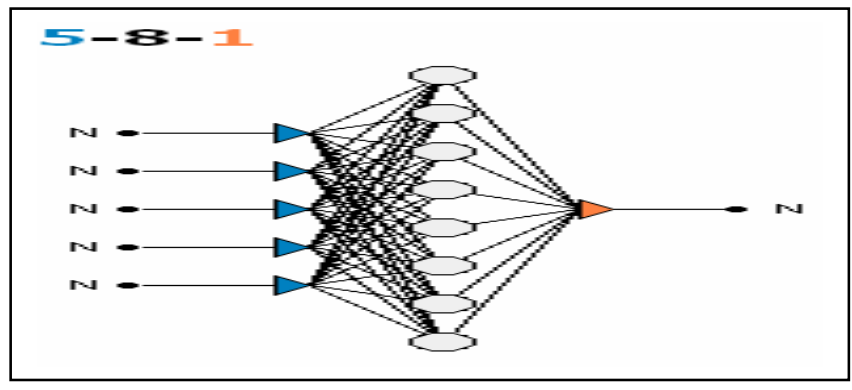

Figure 5: The ANN designed network adopted.

The point rainfall data of each of the four stations as well as the digital average rainfall obtained as above is used as an input data for the ANN network (Figure 6). The corresponding observed three hourly runoff depths have been used for training, testing and validation of the ANN network. 


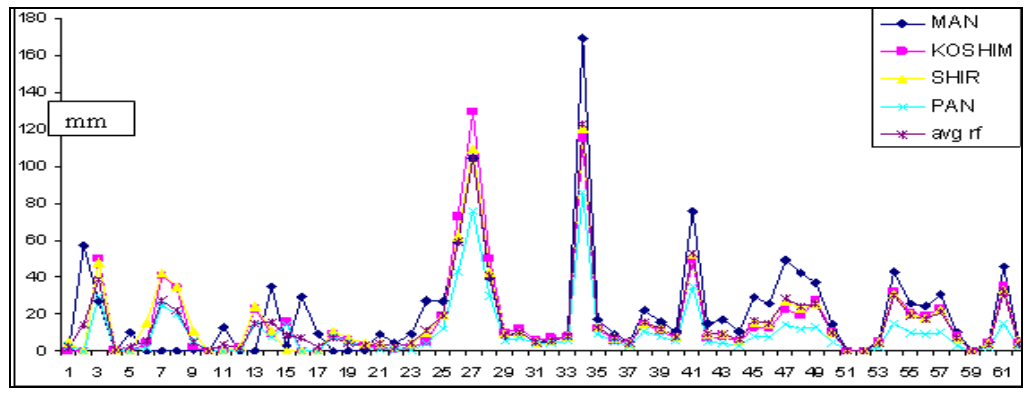

Figure 6: Sample input rainfalls.

\section{ANN output results}

The training, testing and validation results are compared with the concurrent observed runoff depths computed using the concurrent reservoir levels. The results obtained are depicted in Figure 7.

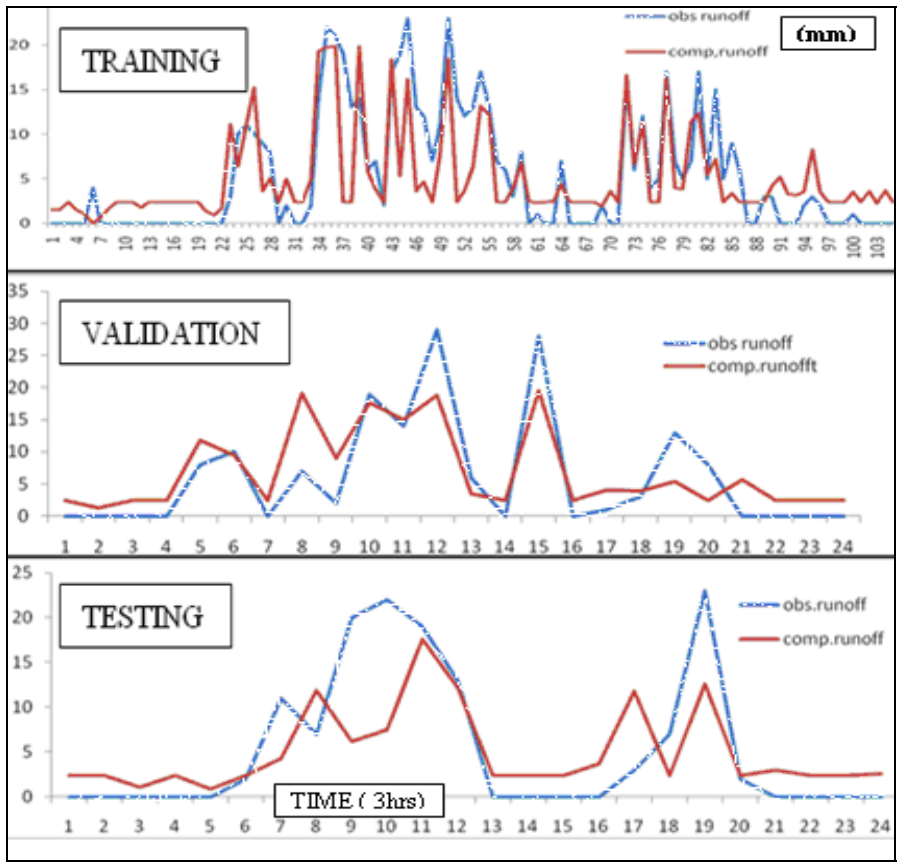

Figure 7: $\quad$ ANN training, validation and testing results.

The sample query average rainfall hyetograph and the corresponding predicted runoff is shown in Figure 8. 


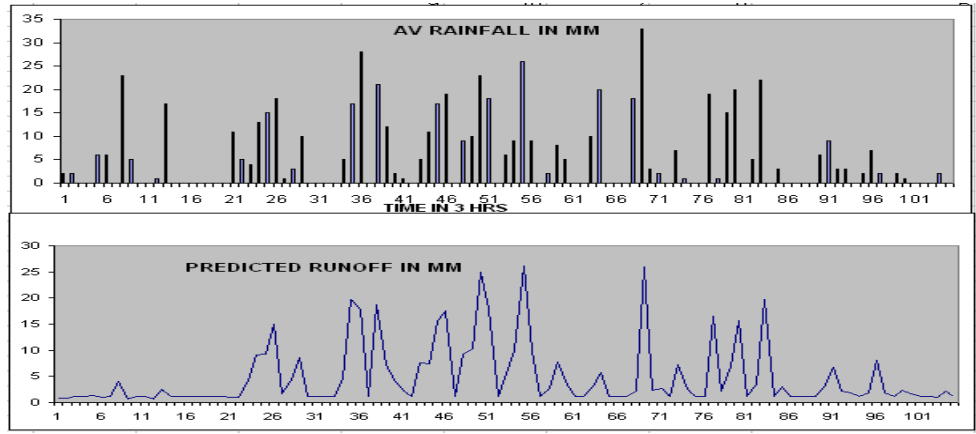

Figure 8: $\quad$ Sample query results.

\section{Conclusion}

The output results as shown in Figure 7 indicate that the observed and computed runoff depths are more or less matching with respect to peaks as well as time. Hence it can be inferred that the design as well as the training, validation and testing of the ANN network is quite satisfactory. The results of the sample query input hyetograph as shown in Figure 8 are also satisfactory. Thus it can be inferred that the trained ANN network with the observed rainfall depths as an inputs can be very well used for runoff forecasting with more accuracy and very short processing time. Further research on remaining aspects of the reservoir inflow forecasting methodology flowchart is under progress.

\section{References}

[1] WMO-UNESCO-XXIV “International Glossary of Terms in Hydrology”WMO (1974)/ (385-II edition- +413PP).

[2] Schumann A.H., R. Funke, G.A. Schultz "Application of GIS for conceptual rainfall runoff modelling” Journal of Hydrology 24045 61(2000).

[3] James E. Ball and Kin Chai Luk "Modeling Spatial Variability of rainfall over a catchment" Journal of Hydrologic Engineering ASCE, 122-130. April 1998.

[4] Narkhedkar et al. "Rainfall analysis using conventional and nonconventional rainfall information on monthly scale” Atmósfera 23(2), 141164(2010).

[5] Sezin Tokar, Peggy A. Johnson "Rainfall - Runoff Modeling using Artificial Neural Network”, - ASCE Journal of Hydrologic Engineering Vol4 No.3 Paper No. 14723 (232-239) July 1999.

[6] Sajikumar N., B.S. Thandaveswara "A Non-Linear rainfall-runoff model using artificial neural network” Journal of Hydrology 216 32-35(1999). 
[7] Cameron M. Zealand, Donald H. Burn, Slobodan, P. Simonovie "Short Term Stream flow forecasting using artificial neural networks" Journal of Hydrology 214 32-48 (1999).

[8] http:/www.alyuda.com/neural-networks-software.htm 